\section{Endodontic Retreatment Using a Single Instrument from four Nickel- Titanium Systems - A Micro-CT Study}

\author{
Marco Antonio Diniz Azevedo ${ }^{1,4}$, Thiago Gomes da Silva ${ }^{2}$, Ângela \\ Fernandes $^{2}{ }^{\circledR}$, Lucila Piasecki ${ }^{3}$, Luiz Fernando Fariniuk ${ }^{4}$, Ulisses Xavier \\ da Silva Neto ${ }^{1}$ (1)
}

This study evaluated the efficiency of using a single instrument from three different rotary multi-file systems and compared them with that of a reciprocating single-file for endodontic retreatment by means of micro-CT. Sixty extracted canines were prepared using a size F2 ProTaper Universal file and obturated. After 30 days of storage at $37^{\circ} \mathrm{C}$ and $100 \%$ humidity, the teeth were randomly divided into four groups $(n=15)$ based on the type of instrument used to retreatment: ProTaper Next (PTN), ProTaper Gold (PTG), TRUShape 3D (TS), and WaveOne (WO). The canals were retreated using only the size 40 instrument from each system according to the manufacturer's recommendations for torque and speed. The time required to remove the filling material was recorded in seconds. The amount of initial and residual filling material and the quantity of dentin removed were assessed by means of micro-CT. Data were statistically analyzed (ANOVA and Kruskal-Wallis) at a $5 \%$ significance level. TS instruments required the highest $(p<0.05)$ amount of time (mean, $384.80 \pm 144.92)$ compared with the WO (229.67 \pm 68.16$)$ and PTG (248.67 \pm 64.22$)$ and not so different from PTN instruments $(327.67 \pm 133.3)$. No differences in the amount of dentin removed, initial and residual filling volume, and percentages of filling material were observed among the groups. The use of a single rotary instrument from the PTG, TS, and PTN systems was as effective as that of the single-file reciprocating WO system. However, none of the instruments was able to remove the filling materials completely.

\author{
${ }^{1}$ Postgraduate Program in \\ Endodontics, School of Health \\ and Biosciences, PUCPR - \\ Pontifícia Universidade Católica \\ do Paraná, Curitiba, PR, Brazil \\ ${ }^{2}$ Federal University of Paraná, \\ UFPR, Universidade Federal do \\ Paraná, Curitiba, PR, Brazil \\ ${ }^{3}$ University at Buffalo, NY, USA \\ ${ }^{4} \mathrm{UP}$ - Universidade Positivo \\ Curitiba, PR, Brazil
}

Correspondence: Marco Antonio Diniz Azevedo, Rua Imaculada Conceição, 1155 80215-901, Curitiba, PR, Brasil. Tel: +55-41-3271-1637. e-mail: doutormarco@gmail.com
Key Words: endodontics, filling material removal, micro-computed tomography, nickel-titanium instruments, retreatment.

\section{Introduction}

The permanence of filling materials in the root canal can compromise the success of an endodontic retreatment procedure because the remaining filling materials that adhere to the dentin walls can shelter microorganisms and necrotic remains leading to the development of intraradicular infection, which can interfere with the adhesion of new filling materials to the walls $(1,2)$.

Various brands and types of nickel-titanium (NiTi) instruments designed specifically for retreatment procedures are available in the market. However, previous studies have shown contradictory findings regarding the performances of these retreatment systems when compared with the conventional shaping files (3-5). Moreover, the combination of different filing systems in a clinical setting is questionable mainly because the canals will need to be further enlarged using shaping instruments after the removal of the filling (4-6). So far, various instruments designed for root canal preparation have been tested for their ability to remove filling materials $(4,5,7-9)$.

The main advantage of using engine-driven file systems over hand files is the reduction in the time required for filling removal $(3,6,9)$. Hence, the use of single-file systems such as WaveOne (WO; Dentsply Sirona, Ballaigues, Switzerland) for endodontic retreatment has been suggested $(7,10)$. This instrument operates in a counterclockwise reciprocating motion with proprietary kinematics that require a specific motor. Reciprocation is known to increase the resistance of endodontic instruments to cyclic fatigue when compared to continuous rotatory motions $(5,6,10)$; however, there are conflicting reports about the efficacy of reciprocating instruments for gutta-percha removal $(7,10)$. Continuous rotation provides adequate penetration of the instrument into the filling material, thereby aiding in the proper removal of the debris. Yet, rotary instruments are generally recommended for use as part of a multi-file system to prevent excessive stress formation $(11,12)$. The currently available single-file rotary instruments present small dimensions (7), thus necessitating the use of additional files to achieve proper cleaning and shaping of oval canals. Moreover, recent advances in the manufacturing process, design, and metallurgy have led to the development of instruments that are more flexible and resistant compared to conventional NiTi files, such as the ProTaper Gold (PTG; 
Dentsply Tulsa Dental Specialities, Johnson City, TN, USA), ProTaper NEXT (PTN; Dentsply Tulsa Dental Specialities), and TRUShape 3D (TS; Dentsply Tulsa Dental Specialities) (12-14).

ProTaper Gold instruments (PTG; Dentsply Tulsa Dental Specialities) features the same design as ProTaper Universal (PTU) instruments (Dentsply Sirona); however, they are manufactured by a proprietary thermomechanical treatment process that improves their mechanical properties, such as flexibility, resistance to cyclic fatigue, and cutting efficiency $(13,14)$.

ProTaper NEXT instruments (PTN; Dentsply Tulsa Dental Specialities) comprise a set of rotary instruments with variable tapers and an off-centered rectangular crosssection, which is intended to reduce the torsional stress on the instrument. The set includes five shaping instruments manufactured from M-Wire alloy, which makes them more resistant to cyclic fatigue when compared with the conventional NiTi files $(12,13)$.

TRUShape 3D (TS; Dentsply Tulsa dental Specialities) instruments are heat-treated and designed to produce an eccentric motion. They have a symmetrical triangular cross-section with a 0.06 taper in the apical $2 \mathrm{~mm}$ and a variable taper along the rest of the file (denoted as $/ .06 \mathrm{v}$ ) $(15,16)$. When activated, TS instruments mold themselves into the canal resulting in less dentinal removal and apical transportation compared to the regular rotary tapered instruments $(15,17)$.

Although the aforementioned instruments are not primally intended for retreatment, few studies have shown that they could be used for this purpose $(8,16,17)$. Moreover, owing to the improved mechanical characteristics of these multi-file rotary instruments, it has been hypothesized that the endodontic retreatment of large oval canals can be performed using only one instrument of compatible size.

Micro-computed tomography (micro-CT) is a nondestructive technology that allows qualitative and quantitative evaluations in the three dimensions of variables such as volume, surface areas, cross-sectional shape, conicity and changes in the prepared surface of the root canals (8-10). Micro-CT is useful to evaluate the internal anatomy of the teeth and the changes in the root canal before and after endodontic procedures (15), as well as the amount of filling material after retreatment procedures $(4,6,8-10,16)$. Thus, the aim of this ex vivo study was to evaluate the effects of using only one rotary instrument from the three different endodontic multi-file systems (PTG, PTN, and TS) and compare them with the reciprocating single-file system (WO) for the endodontic retreatment of mandibular canines. In addition to the operative time, the amount of filling material left in the canal and quantity of dentin removed were assessed by means of micro-computed tomography (micro-CT).

\section{Material and Methods}

Ninety-five human, single-rooted canines were selected from a pool of extracted teeth stored in a $0.5 \%$ chloramine solution in accordance with the approval by the local ethics committee (protocol 1.354.647/2015). Sixty extracted human single-rooted canines stored in 0.5\% chloramine solution were collected for this study. The teeth were washed in running water and all the soft and hard tissue remnants on the root surfaces were removed. Teeth with immature apices, resorptive defects, extensive caries, root fillings, cracks, calcifications, or apical curvatures greater than $10^{\circ}$ were excluded. Periapical digital radiographs (Kodak RVG 5100, Carestream Health, Inc., Rochester, NY) were taken in both mesiodistal and buccolingual planes to confirm the presence of a single oval canal, defined by a ratio greater than 2 (of the maximum to the minimum canal diameter) obtained at the transversal slice located $5 \mathrm{~mm}$ from the apex $(7,10)$. Finally, sixty standardized teeth characterized by Vertucci's Type I configuration, apical curvature less than $10^{\circ}$ and oval canals were selected.

\section{Root Canal Preparation and Obturation}

The crowns were cut to obtain a reproducible coronal reference and to standardize the lengths of the specimens (approximately $20 \pm 2.0 \mathrm{~mm}$ ). After a conventional endodontic access opening was made, the patency was checked using a size 15, manual K-file (Dentsply Maillefer). The file was inserted up to the apical foramen (AF) under $4 \times$ magnification using an operating microscope (DF Vasconcellos, Londrina, PR, Brazil). The working length (WL) was determined as $1 \mathrm{~mm}$ short of the AF.

The root canals were initially prepared using the NiTi rotary ProTaper Universal (PTU) instruments (Dentsply Sirona), up to a size F2 (25/.08), according to the manufacturer's instructions. The canals were irrigated with $2.5 \%$ sodium hypochlorite, which was delivered using a 30G side-vented needle (NaviTip; Ultradent Products, South Jordan, UT, USA) inserted up to $1 \mathrm{~mm}$ short of the $W L$, and aspiration performed using endodontic plastic tips. Final irrigation was performed using 17\% EDTA (CanalPro, Coltene-Endo, Cuyahoga Falls, OH, USA). The canals were dried with paper points and obturated with gutta-percha and AH Plus sealer (Dentsply De Trey, Konstanz, Germany) using the Tagger's hybrid technique. The access cavities were then sealed using a temporary restorative material (Citodur, Dorident, Vienna, Austria). The specimens were stored at $37{ }^{\circ} \mathrm{C}$ and $100 \%$ humidity conditions for at least 30 days (between 30 and 45 days) before initiating the retreatment procedure. 


\section{Retreatment Procedures}

The specimens were randomly divided into four groups $(n=15)$ using a random number generator (www.random. org), based on the type of instruments used, as follows: PTN group, PTN file X4 (size 40/.06) was used at a speed of 300 rotations per min (rpm) and a torque of $2 \mathrm{Ncm}$; PTG group, PTG F4 (size 40/.06v) file was used at a speed of $300 \mathrm{rpm}$ and a torque of $3.1 \mathrm{Ncm}$; TS group, TS 3D (size 40/.06v) file was used at a speed of $300 \mathrm{rpm}$ and a torque of $3 \mathrm{Ncm}$; and WO group, WO Large (size 40/.08) file was operated in a reciprocating WaveOne All motion. The instruments were powered by an endodontic motor (X-Smart Plus, Dentsply Sirona).

The retreatment procedures were performed by a single experienced endodontist using a dental operating microscope. The temporary restorative material was removed using round burs and retreatment was initiated by instrumenting through the gutta-percha using light apical pressure in an attempt to remove all the filling material and reach the WL. Once the WL was reached, a brushing action was used against the lateral canal walls until there was no filling material adhered to the instrument or the canal walls. At the end of the procedure, the patency was confirmed using a size $15 \mathrm{~K}$-file. Irrigation was performed throughout the instrumentation process using a total of 5 $\mathrm{mL}$ of $2.5 \%$ sodium hypochlorite, and aspiration performed using endodontic plastic tips. New instruments were used for each canal. For all the preparation and retreatment procedures, the teeth were fixed using a mounting vise. The total time required for the retreatment procedure was recorded in seconds (s) using a digital chronometer.

\section{Micro-CT Scanning and Analysis}

The specimens were fixed in $20 \mathrm{~mm}$ thick extruded polystyrene plates (XPS model, Neotérmica, São Paulo, Brazil) to ensure the reproducibility of the position for the pre and post-retreatment micro-CT scans (SkyScan 1172, Bruker-microCT, Kontich, Belgium). The X-ray source was set at $89 \mathrm{kV}$ of accelerating potential and $112 \mu \mathrm{A}$ anode current, using an aluminum filter.
The scanning stage was set to capture images every $0.4^{\circ}$ of a $180^{\circ}$ rotation, using a $0.3 \mathrm{sec}$ exposure time to yield images with an isotropic resolution of 27.78 $\mu \mathrm{m}$. The scanned data was reconstructed to form threedimensional (3D) projections using the NRecon v.1.7.0.4 64-bit (Bruker-microCT). Pre- and post- stacks of images were geometrically aligned using $3 \mathrm{D}$ registration software (Data Viewer 1.5.2.4, Bruker microCT) with a shift step of 0.5 pixels and a rotation of $0.1^{\circ}$. Quantitative two and three-dimensional analyses of the scans were performed by a calibrated operator (CT Analyzer v.1.16.1.0+, BrukermicroCT). The volume of interest was established from the cementoenamel junction up to $1 \mathrm{~mm}$ short of the most coronal slice showing the AF. A segmentation threshold was used to identify and measure the volume $\left(\mathrm{mm}^{3}\right)$ of the filling material and dentin in the pre- and postretreatment scans. The amount of remaining filling materials after the retreatment procedures were expressed as a percentage of the total initial root filling volume. The amount of dentin removed was calculated by subtracting the dentin volume $\left(\mathrm{mm}^{3}\right)$ in the pre- and post- scans.

\section{Statistical Analysis}

Statistical analysis was performed using the SPSS software version 23.0 for Windows (SPSS Co., Chicago, IL, USA), at a $5 \%$ significance level. Data regarding operation time was normally distributed (Shapiro-Wilk test, $p>0.05$ ) and homoscedastic (Levene's test, $p>0.05$ ); thus, one-way analysis of variance (ANOVA) test was employed for the comparison among groups. The post-hoc Games-Howell test was used to analyze the other variables that presented heterogeneous variance (volume and percentage of initial and residual filling, and dentin removal).

\section{Results}

Statistically significant differences in operation time were observed among the four groups (Table 1). The TS group required the highest mean time $(384.80 \pm 144.92)$ when compared with the other groups: WO $(229.67 \pm 68.16)$, PTG $(248.67 \pm 64.22)(p<0.05)$ and not so different from PTN group $(327.67 \pm 133.3)$ ( $p>0.05)$.

No statistically

Table 1. Descriptive (mean and standard deviation) for the initial and residual volume $\left(\mathrm{mm}^{3}\right)$ and percentage $(\%)$ of the remaining filling material, dentin removed after preparation $\left(\mathrm{mm}^{3}\right)$, and operating time (s) per group

\begin{tabular}{|c|c|c|c|c|c|c|}
\hline \multirow{2}{*}{ Groups } & \multirow{2}{*}{$n$} & \multicolumn{3}{|c|}{ Volume of filling material } & \multirow{2}{*}{$\begin{array}{l}\text { Dentin } \\
\text { removed }\left(\mathrm{mm}^{3}\right)\end{array}$} & \multirow{2}{*}{ Time (s) } \\
\hline & & Initial $\left(\mathrm{mm}^{3}\right)$ & Residual $\left(\mathrm{mm}^{3}\right)$ & Remaining (\%) & & \\
\hline PTN & 15 & $21.46( \pm 5.13)^{a}$ & $1.22( \pm 1.04)^{a}$ & $5.22( \pm 4.19)^{\mathrm{a}}$ & $5.03( \pm 1.58)^{a}$ & $327.67( \pm 133.30)^{a b}$ \\
\hline PTG & 15 & $21.69( \pm 4.72)^{a}$ & $0.92( \pm 0.71)^{a}$ & $4.12( \pm 3.17)^{a}$ & $3.58( \pm 2.01)^{a}$ & $248.67( \pm 64.22)^{a}$ \\
\hline TS & 15 & $22.64( \pm 4.76)^{a}$ & $1.02( \pm 1.47)^{a}$ & $4.41( \pm 7.48)^{\mathrm{a}}$ & $4.58( \pm 2.22)^{a}$ & $384.80( \pm 144.92)^{b}$ \\
\hline WO & 15 & $19.01( \pm 4.36)^{\text {a }}$ & $1.07( \pm 2.13)^{a}$ & $5.27( \pm 10.12)^{a}$ & $4.89( \pm 1.62)^{a}$ & $229.67( \pm 68.16)^{\mathrm{a}}$ \\
\hline
\end{tabular}

Different superscript letters indicate a statistically significant within column $(p<0.05)$. significant differences in the initial and residual volume $\left(\mathrm{mm}^{3}\right)$, and percentage $(\%)$ of remaining filling material were noted among the groups ( $p>0.05$ ); likewise, the volume $\left(\mathrm{mm}^{3}\right)$ of dentin removed was similar across 
the four groups. Pearson's correlation coefficient indicated a statistically significant positive correlation $(r=0.55$, $p=0.034$ ) between the percentage of remaining filling material and operation time in the PTG group.

Figure 1 shows 3D micro-CT scans and the canal crosssections of the representative specimen of each group of the endodontic retreatments.

\section{Discussion}

The removal of the previous obturation materials during non-surgical endodontic retreatment is essential to gain access to the root canals and disinfect them $(1,2)$. The ability of an instrument or technique to remove filling materials from the root canals has been evaluated by different methods $(3,7,17,18)$; however, micro-CT is considered as the most accurate method owing to possibility of performing $3 \mathrm{D}$ sequential qualitative and quantitative evaluations $(4,6,8-10,15,16,19-24)$. Although the use of many different instruments has been proposed and investigated, none has resulted in completely freeing the root canal system of the endodontic filling material (3-9,16-25).

The results of the present study corroborate these findings with an overall mean percentage of remaining filling material of $4.75 \%$. Thus, other factors such as efficiency and or cost become more relevant for the clinician while choosing an instrument to perform endodontic retreatment.

The main advantage of using engine-driven file systems over hand files is the reduction in the time required for filling removal $(3,6,9)$. Single-file systems were developed to make the endodontic shaping procedure faster, safer, and avoid cross-infection $(4,7,10,16)$. Previous studies have shown that WO files are similar to other rotary and reciprocation systems for the removal of gutta-percha from the root canals $(4-6,10,20)$. In the current study, the mean percentage of remaining filling material using the WO instrument was 5.26\%, which is within the range reported in the literature $(2.98 \%-26.65 \%)$ for this instrument and for the heat-treated version of this file, WaveOne Gold (4$7,10,21)$; however, the efficiency of this file for retreatments compared to rotary files is still controversial $(4,6,7,21)$.

The ability to remove gutta-percha is correlated to features such as the design, cutting efficiency, and kinematics of the instrument $(7,14)$. In the present study, the PTN files have a rectangular cross-section (19) while the other investigated instruments have a triangular crosssection $(5,13-15)$. It has been suggested that the design of the WO file hinders its penetration into the canal and may not enable adequate debris removal, $(4,7)$, which might also be correlated to a higher incidence of fractures when used for removing filling materials (7). Previous studies have suggested that continuous rotation provides a more suitable cutting motion for retreatment cases $(7,10)$. Moreover, the single-file reciprocating WO files are meant to be used with proprietary kinematics software that requires a specific motor. Thus, in order to overcome some of the limitations of the use of the reciprocating singlefile system, we investigated the use of a single rotary instrument (from a multi-file rotary system) for the removal of gutta-percha from the root canals.

Overall, the results of this study indicate that the performances of the tested rotary instruments (PTN, PTG, and TS) were comparable to that of WO regarding the
Figure 1. Micro-CT scans. A, B and C: lateral views of representative three-dimensional reconstructions of mandibular canines in each experimental group showing the filling material (pink) in the root canals before (A) and after (B, C) retreatment procedures. C: Final shape of the canals after retreatment showing the removed dentin (green). D: Representative cross sections of the root canals post-retreatment showing the remaining filling material (pink) and the removed dentin (green) at the coronal (c), middle (m), and apical (a) thirds. 
amount of filling material remaining in the canal and the volume of dentin removed after the retreatment procedures. About the procedural time, the TS files required significantly more time than the WO and PTG instruments (Table 1). TS files feature an off-centered cross-sectional design that when activated creates a snake-like movement (15), which was more efficient to remove filling material compared to Vortex Blue instruments during the retreatment of mandibular premolars through contracted access, but not for conventional endodontic cavity (17). In the present study, using traditional access, TS resulted in similar amount of remaining filling material but required significantly more time. These findings agree with a previous micro-CT evaluation in which TS files presented similar efficacies for the retreatment of mandibular canines, but required more time compared to the Reciproc instruments (16). Although variations in results among the different retreatment studies might be related to the variations in the methodologies, study designs, sample selections, and types of sealers and obturation techniques used $(16,18,25)$, the diminished efficiency of the TS files for retreatment may be related to its eccentric motion, which reduces the screw-in force and the contact of the instrument with the dentinal walls, thus increasing the operating time.

In a previous micro-CT study, $1.47 \%$ of the filling material was left in the canals of mandibular premolars using the full sequence of the PTN instrument (up to file X4) for retreatment (8). The results of using the PTN files were comparable to that of the reciprocating single-file system (Reciproc, VDW); however, the operating time was not reported in the study (8). In the present study, mean percentage of remaining filling material following the use of a single, size 40 PTN instrument was $5.22 \%( \pm 4.19)$, which was similar to percentages obtained from the other tested files. PTN presented intermediate results with regard to the operating times of the files tested in this study. All the files were operated at same speed; hence, the minor differences in time are likely related to design and the eccentric motion of the PTN file.

Mechanical tests have shown that gold heat treatment improves the flexibility, resistance, and cutting efficiency of the PTG instruments when compared with the PTU instruments $(13,14)$. In the present study, the PTG file removed slightly greater amounts of filling material and lower amounts of dentin from the canals when compared with the other instruments, statistical significance notwithstanding. To the best of our knowledge, the use of PTG instruments for retreatment has not been evaluated so far. The performances of other heat-treated files, such as WO Gold and Reciproc Blue, were not superior to those of their M-wire counterparts, WO and Reciproc $(19,25)$. However, no direct correlation could be drawn between present results and the findings of a previous study because of the difference in the kinematics since those past studies evaluated reciprocating instruments, different from PTG used in the present study, which is a rotary gold-treated file (19). Nevertheless, our results could also be correlated to the fact that the initial root canal preparation of the samples was performed using files of identical design of PTG, ProTaper Universal.

During retreatment, the canals should be enlarged up to two sizes wider than the initial apical diameter in order to improve the cleanliness of the canals $(4,20)$ and prevent extensive enlargement (4). In the present study, the choice of size 40 instruments ensured that the apical diameter was enlarged by at least $0.1 \mathrm{~mm}$ for all the samples (8). Although the WO instruments presented with the largest taper among the files tested in this study, the total amount of dentin removed was similar in all the four groups. Clinically, the results of this study could be translated as a simplified and more cost-effective method for the management of nonsurgical retreatment cases, dispensing the need for different sets of instruments. However, it is important to highlight that the results of this investigation were obtained in a laboratory setting under controlled conditions and limited to oval canals of mandibular canines; thus, they should not be directly extrapolated to a clinical scenario or to other types of teeth. Future investigations are required to validate the proposed retreatment protocol for other types of teeth and different anatomic complexities in a clinical setting.

Within the limitations of this ex vivo study, none of the tested instruments was able to completely remove the filling material from the oval canals. The results of the use of only one instrument from the multi-file rotary systems (PTG, PTN, and TS) for endodontic retreatment were similar to that of the reciprocating single-file WO system with regard to gutta-percha removal and canal enlargement (dentin removed). TS instruments required significantly more operating time compared to the WO and PTG instruments and not so different from PTN instruments.

\section{Resumo}

Este estudo laboratorial avaliou por meio de micro-CT a eficiência do uso de um único instrumento de três sistemas rotatórios em retratamentos endodônticos, comparados a um instrumento único reciprocante. Sessenta caninos extraidos foram preparados usando o sistema ProTaper Universal (F2) e obturados. Após 30 dias de armazenamento a $37^{\circ} \mathrm{C}$ e $100 \%$ de umidade, os dentes foram divididos aleatoriamente em quatro grupos (n = 15), de acordo com o instrumento utilizado para remover as obturações endodônticas: ProTaper NEXT (PTN), ProTaper Gold (PTG), TRUShape 3D (TS) e WaveOne (WO). Os canais foram retratados usando apenas o instrumento tamanho 40 de cada sistema, seguindo as recomendações do fabricante para torque e velocidade. 0 tempo necessário para remover a obturação foi registrado em segundos. A quantidade de material remanescente e o volume de dentina removida foram avaliadas por meio de micro-CT. Análise estatística foi realizada (ANOVA e Kruskal-Wallis), com nivel de significância de 5\%. 0 tempo de trabalho no grupo TS foi 
significativamente maior $(\mathrm{p}<0.05)$ (média, 384,80 \pm 144,92) comparado a WO $(229,67 \pm 68,16)$ e PTG $(248,67 \pm 64,22)$, e similar a PTN $(327,67 \pm$ $133,3)$. Não houve diferenças entre os grupos na quantidade de dentina removida e nas porcentagens de material obturador residual. 0 uso de apenas um instrumento rotatório dos sistemas PTG, TS e PTN foi tão eficaz quanto o do sistema WO reciprocante na remoção do material obturador. No entanto, nenhum dos instrumentos conseguiu remover completamente os materiais obturadores.

\section{Acknowledgements}

The authors would like to thank CAPES/MEC, Brazilian government for financial support.

\section{References}

1. Virdee SS, Thomas MB. A practitioner's guide to gutta-percha removal during endodontic retreatment. Braz Dent J 2017;222:251-257.

2. Wu MK, Dummer PM, Wesselink PR. Consequences of and strategies to deal with residual post-treatment root canal infection. Int Endod J 2006:39:343-356.

3. Fariniuk LF, Azevedo MAD, Carneiro E, Westphalen VPD, Piasecki L, da Silva Neto UX. Efficacy of protaper instruments during endodontic retreatment. Indian J Dent Res 2017;28:400-405.

4. Delai $D$, Jardine AP, Mestieri LB, Boijink D, Fontanella VRC, Grecca FS, et al. Efficacy of a thermally treated single file compared with rotary systems in endodontic retreatment of curved canals: a micro-CT study. Clin Oral Investig 2019;23:1837-1844.

5. Rios M de A, Villela AM, Cunha RS, Velasco RC, De Martin AS, Kato AS, et al. Efficacy of 2 reciprocating systems compared with a rotary retreatment system for gutta-percha removal. J Endod 2014;40:543546.

6. Helvacioglu-Yigit D, Yilmaz A, Kiziltas-Sendur G, Aslan OS, Abbott PV. Efficacy of reciprocating and rotary systems for removing root filling material: a micro-computed tomography study. Scanning 2014;36:576-581.

7. Azim AA, Wang HH, Tarrosh M, Azim KA, Piasecki L. Comparison between Single-file Rotary Systems: Part 1-Efficiency, Effectiveness, and Adverse Effects in Endodontic Retreatment. J Endod 2018;44:17201724.

8. Martins MP, Duarte MA, Cavenago BC, Kato AS, da Silveira Bueno CE. Effectiveness of the ProTaper Next and Reciproc Systems in Removing Root Canal Filling Material with Sonic or Ultrasonic Irrigation: A Micro-computed Tomographic Study. J Endod 2017;43:467-471.

9. Rossi-Fedele G, Ahmed HM. Assessment of root canal filling removal effectiveness using micro-computed tomography: A Systematic Review. J Endod 2017;43:520-526.

10. Crozeta BM, Silva-Sousa YT, Leoni GB, Mazzi-Chaves JF, Fantinato T,

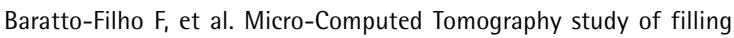
material removal from ovalshaped canals by using rotary, reciprocating, and adaptive motion systems. J Endod 2016;42:793-797.

11. Gambarini G, Plotino G, Piasecki L, Al-Sudani D, Testarelli L, Sannino G. Deformations and cyclic fatigue resistance of nickel-titanium instruments inside a sequence. Ann Stomatol 2015;6:6-9.
12. Pereira $E S$, Singh $R$, Arias $A$, Peters $\mathrm{OA}$. In vitro assessment of torque and force generated by novel ProTaper Next Instruments during simulated canal preparation. J Endod 2013;39:1615-1619.

13. Uygun AD, Kol E, Topcu MK, Seckin F, Ersoy I, Tanriver M. Variations in cyclic fatigue resistance among ProTaper Gold, ProTaper Next and ProTaper Universal instruments at different levels. Int Endod J 2016;49:494-499.

14. Vasconcelos RA, Arias A, Peters OA. Lateral and axial cutting efficiency of instruments manufactured with conventional nickel-titanium and novel gold metallurgy. Int Endod J 2018;51:577-583.

15. Peters $\mathrm{OA}$, Arias A, Paque F. A Micro-computed tomographic assessment of root canal preparation with a novel instrument, trushape, in mesial roots of mandibular molars. J Endod 2015;41:1545-1550.

16. de Siqueira Zuolo A, Zuolo ML, da Silveira Bueno CE, Chu R, Cunha RS. Evaluation of the efficacy of trushape and reciproc file systems in the removal of root filling material: an ex vivo micro-computed tomographic study. J Endod 2016;42:315-319.

17. Niemi TK, Marchesan MA, Lloyd A, Seltzer RJ. Effect of instrument design and access outlines on the removal of root canal obturation materials in oval-shaped canals. J Endod 2016;42:1550-1554.

18. Baratto Filho F, Ferreira EL, Fariniuk LF. Efficiency of the 0.04 taper ProFile during the re-treatment of gutta-percha-filled root canals. Int Endod J 2002;35:651-654.

19. Canali LCF, Duque JA, Vivan RR, Bramante CM, Só MVR, Duarte MAH. Comparison of efficiency of the retreatment procedure between wave one gold and wave one systems by micro-ct and confocal microscopy: an in vitro study. Clin Oral Investig 2019;23:337-343.

20. Da Rosa RA, Santini MF, Cavenago BC, Pereira JR, Duarte MA, Só MVR. Micro-CT Evaluation of root filling removal after three stages of retreatment procedure. Braz Dent J 2015;26:612-618.

21. Fruchi LC, Ordinola-Zapata $R$, Cavenago $B C$, Duarte $M A H$, Bueno $C E$, De Martin AS. Efficacy of reciprocating instruments for removing filling material in curved canals obturated with a single-cone technique: a micro-computed tomographic analysis. J Endod 2014;40:1000-1004.

22. Monguilhott Crozeta B, Damiao de Sousa-Neto M, Bianchi Leoni G, Francisco Mazzi-Chaves J, Terezinha Correa Silva-Sousa Y, BarattoFilho F. A micro-computed tomography assessment of the efficacy of rotary and reciprocating techniques for filling material removal in root canal retreatment. Clin Oral Investig 2016;20:2235-2240.

23. Roggendorf $\mathrm{MJ}$, Legner $\mathrm{M}$, Ebert J, Fillery $\mathrm{E}$, Frankenberger R, Friedman S. Micro-CT evaluation of residual material in canals filled with Activ GP or GuttaFlow following removal with NiTi instruments. Int Endod J 2010:43:200-209.

24. Yilmaz F, Koc $C$, Kamburoglu $K$, Ocak M, Geneci F, Uzuner MB, et al. Evaluation of 3 different retreatment techniques in maxillary molar teeth by using microcomputed tomography. J Endod 2018;44:480-484

25. Romeiro K, de Almeida A, Cassimiro M, Gominho L, Dantas E, Chagas $\mathrm{N}$, et al. Reciproc and Reciproc Blue in the removal of bioceramic and resin-based sealers in retreatment procedures. Clin Oral Investig 2020;24:405-416. 